\title{
COLOMBIA: REFORMA AGRARIA EN LA SOLUCIÓN DE CONFLICTOS ARMADOS
}

\author{
Darío Fajardo Montaña*
}

\section{INTRODUCCIÓN}

Luego de varios años de relegamiento de la problemática agraria, como resultado de las tendencias que se impusieron en la política macroeconómica de una gran mayoría de países, Colombia debió considerarla de nuevo, dada la incidencia que gran número de factores de base rural venían mostrando sobre el desempeño político, económico y social de la nación. Dentro de estos factores, complejos e íntimamente relacionados se destacan: la pobreza rural, característicamente más extendida y profunda que la urbana; el conflicto armado, que si bien tiene manifestaciones en los medios citadinos, se desenvuelve en el campo con marcada virulencia e impactos de mayores alcances y, por último, la marcada desinstitucionalización que afecta al conjunto de la vida económica y social del mundo rural.

Estos factores, complejos en sus estructuras, han recibido tratamientos aparentemente inadecuados que no se han traducido en su efectiva superación; por el contrario, dan muestra de agudizarse y, en esa medida muestran también su capacidad para desestabilizar al conjunto de la sociedad. En la actual coyuntura, cuando termina uno de los más agitados períodos presidenciales de los últimos años, envuelto en una crisis relacionada con buena parte de los factores de nuestro diagnóstico, adquiere importancia especial la discusión sobre los alcances de esta crisis, el análisis de su naturaleza y la presentación y examen de propuestas dirigidas a su superación.

Este ensayo, cuya primera versión fue elaborada con el auspicio de la Fundación Friedrich Ebert de Colombia, expone las líneas básicas del diagnóstico, elaboradas a partir de algunos de los trabajos mas representativos, examina sus bases políticas y, por último, pone en consideración las tareas que sería necesario abocar para sentar las bases de una paz duradera, sustentada en una construcción más equilibrada de las relaciones económicas y políticas de la sociedad colombiana y, en particular, de su mundo rural.

\section{POBREZA, NARCOTRÁFICO Y VIOLENCIA EN LA CRISIS AGRARIA}

A mediados del segundo año de la administración del Presidente Samper, el Ministerio de Agricultura impulsó un conjunto de compromisos del gobierno en torno a la agricultura y el mundo rural (Contrato Social Rural), sustentados en algunos diagnósticos básicos que destacaban la elevada incidencia de la pobreza en el campo, las magnitudes de los nuevos patrones de concentración de la propiedad rural y sus relaciones con el conflicto armado, el papel del narcotráfico en la crisis agraria y la debilidad de las instituciones responsables de la gestión del desarrollo del campo.

Existe un conjunto apreciable de información en torno al diagnóstico de la situación social del campo, contradictoria en algunos aspectos, pero coincidente en destacar como rasgo dominante, la persistencia de condiciones de pobreza más amplias y acentuadas que las de los medios urbanos, en términos del ingreso de los individuos y de los hogares y del acceso a los servicios públicos (May, 1995).

Esta imagen de una brecha social, que se sostiene en el tiempo y se amplía en el espacio, además de tener ocurrencia en Latinoamérica (Figueroa, 1996) es un componente común a los países en procesos de modernización (Huntington, 1968), pero en Colombia se asocia con los fenómenos que han facilitado el arraigo de la violencia y de la narcoeconomía, los cuales reducen, sin duda, las posibilidades de supervivencia del modelo político y social vigente.

Al mediar la década de 1990, Colombia había ensayado ya varias estrategias para resolver su "cuestión agraria", para afrontar la adecuación del campo a las transformaciones de la economía inducidas por condicionantes externos e internos. Luego de dos lustros de aplicación de una reforma agraria marginal, en los términos de Antonio García $(1970,1982)$, las políticas para la modernización del campo se orientaron, en lo referente al sector campesino, hacia el Desarrollo Rural Integrado (DRI). Sus efectos fueron positivos, pero muy discretos en cuanto a las poblaciones atendidas e incrementos en producción, productividad, superación de la pobreza y de las "brechas tecnológicas".

La decisión de impulsar las estrategias DRI precedió a la del desmonte de la reforma agraria, a su sustitución por el reforzamiento de la aparcería y al impulso de programas de colonización en las fronteras, opciones encaminadas a del IICA. 
mantener incólume la estructura de la propiedad. Pocos años más tarde, el Estado habría de acudir a nuevos programas para las áreas rurales con los cuales tratar de remediar los profundos desajustes creados en los territorios marginales de la colonización, como lo han sido el Plan Nacional de Rehabilitación (PNR) y los Programas de Sustitución de cultivos ilícitos y Desarrollo Alternativo.

Estos planes y programas desplazaron, entonces, a la reforma agraria, cada vez mas disminuida en sus alcances y recursos, al tiempo que el discurso económico y político oficial subvaloraba, de manera y creciente, cualquier consideración sobre la misma. No obstante, la agudización de los conflictos en el campo ha traído de nuevo, una y otra vez, la pertinencia del reparto agrario, acompañado de los demás componentes de la reestructuración productiva del campo.

Al igual que en otras coyunturas en las cuales se han planteado propuestas de reforma agraria, solamente unas pocas voces se han apartado del consenso a su favor. No obstante, al acercarse el cuarto año de promulgada la Ley 160/1994, es muy poco lo logrado en su aplicación. Formalmente han incidido en el incumplimiento de este mandato legal su lenta reglamentación, la inadecuación de las instituciones, equipos y métodos dispuestos para su aplicación, todo lo cual refleja, en alguna medida, la dimensión del interés nacional al respecto. Pero, en términos reales, gravitan sobre el desempeño de la reforma, los intereses económicos y políticos de los terratenientes y su enorme poder corruptor e intimidatorio.

Se abre, así, una dicotomía entre la voluntad acogida por los legisladores y plasmada en dicha ley y la valoración que hacen otros sectores nacionales de su aplicación. En este punto conviene examinar el contexto que ofrece el país en torno a la reforma agraria.

Entre finales de los ochenta y principios de esta década se produjeron varios análisis de distinto alcance sobre el comportamiento del sector agropecuario y sus tendencias (Misión de Estudios del Sector Agropecuario, 1989; Moscardi et al., 1994, etc.) en donde resaltaban los procesos de especialización regional, las limitaciones de la producción nacional para atender la demanda interna y encontrar ubicación en los mercados internacionales, las características de los mercados laborales y los efectos de las violencias sobre la economía agraria. A pesar de haber sido aprobada poco antes otra ley sobre reforma agraria (Ley 30 de 1987), la cual había alcanzado un variopinto respaldo político, sus ejecutorias no llamaron la atención de los analistas y poco interés despertó en estos ejercicios el tema del reparto agrario.

\section{SITUACIÓN ECONÓMICA Y SOCIAL DE LA POBLACIÓN RURAL DE COLOMBIA}

\section{Crisis de la agricultura}

En 1993 se generó un relativo consenso en torno a la crisis del sector agrícola en Colombia. El Producto Interno Bruto (PIB) agropecuario cayó en $2 \%$, pero la naturaleza de la crisis fue heterogénea: en productos, en sus dimensiones regionales y en los factores que la generaron. En ese año, además de las medidas de la apertura, confluyó otra serie de factores que hace difícil trazar una relación lineal entre las políticas de apertura y la crisis del sector agropecuario. A una severa y prolongada sequía iniciada a mediados del 91, se añadieron la caída en los precios internacionales, tanto de productos exportables como de los productos importables, la revaluación de la tasa de cambio, la reducción y el encarecimiento del crédito, la intensificación de la violencia rural, el desmantelamiento de las entidades promotoras de desarrollo social, la crisis de la Caja Agraria, los efectos mismos de la integración andina, las dificultades de algunos sectores para ajustarse a las nuevas políticas macroeconómicas y sectoriales, las dificultades generadas por el ajuste en los precios relativos, producto de la liberación del comercio, el deterioro en el gasto social rural y los problemas fitosanitarios de distinta índole, entre los cuales se destaca la broca en el café.

Esta crisis implicó la pérdida de 230 mil puestos de trabajo durante los primeros años de la década de los 90. El descenso del empleo rural estuvo acompañado de una caída significativa en los ingresos de los hogares rurales, tanto en ganancias como en salarios, lo que se tradujo en un incremento de la población bajo la línea de pobreza, la cual, entre 1991 y 1995 pasó del 65\% al 72 \% (ver cuadro), y en una ampliación de la brecha entre ingresos rurales y los ingresos urbanos. En el período 1990-93, la diferencia entre los ingresos reales per cápita del sector rural y urbano se amplió a 36 puntos porcentuales. Esta brecha es la mayor que se ha registrado en Colombia en las últimas cuatro décadas. En 1950, el ingreso urbano per cápita era tres veces mayor que el rural; en 1977, la relación había disminuido a 1.7 veces y para 1993 se incrementa a 3.5 veces. En términos de la pobreza rural medida por ingresos, entre 1990 y 1994 el porcentaje de personas pobres en las zonas rurales aumentó del $67 \%$ al $72 \%$.

Es importante señalar que, si bien en Colombia continúa la "desruralización” de su población, el campo todavía alberga a 15 millones de personas, equivalente al 38\% de la población total. Igualmente, el empleo se desplaza desde la agricultura hacia otras actividades, tal como ocurre en todas las economías en transición, pero aún representa mas del $60 \%$ de la ocupación rural, si bien en el país esta proporción es inferior a la de otras economías con grados similares de desarrollo.

\begin{tabular}{|c|c|cc|c|cc|c|c|c|}
\hline \multicolumn{10}{|l|}{ CUADR0 1 } \\
\hline \multicolumn{10}{|c|}{ POBLACIÓN BAJO LÍNEA DE POBREZA POR CABECERAS Y ESTO, 1972 - 1995 } \\
\hline & Total Nacional & & \multicolumn{2}{|c|}{ Cabeceras municipales } & \multicolumn{2}{|c|}{ Resto } & & \\
\hline Año & Población & Bajo & LP & Población & Bajo & LP & Población & Bajo & LP \\
\hline & miles & miles & $\%$ & miles & miles & $\%$ & miles & miles & $\%$ \\
\hline 1972 & 22008 & 13215 & 60.0 & 13053 & 6696 & 51.3 & 8955 & 6519 & 72.8 \\
\hline 1975 & 23757 & 13915 & 58.6 & 14284 & 7142 & 50.0 & 9472 & 6773 & 71.5 \\
\hline 1978 & 25440 & 14335 & 56.3 & 16125 & 7829 & 48.6 & 9315 & 6507 & 69.9 \\
\hline 1986 & 30024 & 15614 & 52.0 & 20138 & 8901 & 44.2 & 9887 & 6713 & 67.9 \\
\hline 1988 & 31141 & 16659 & 53.5 & 21332 & 10047 & 47.1 & 9810 & 6612 & 67.4 \\
\hline 1991 & 32841 & 17041 & 51.9 & 22660 & 10424 & 46.0 & 10181 & 6617 & 65.0 \\
\hline 1992 & 33392 & 17881 & 53.5 & 23127 & 10742 & 46.4 & 10265 & 7139 & 69.5 \\
\hline 1993 & 33952 & 17384 & 51.2 & 23596 & 10052 & 42.6 & 10356 & 7332 & 70.8 \\
\hline 1995 & 35098 & 18391 & 52.4 & 24569 & 10810 & 44.0 & 10529 & 7581 & 72.0 \\
\hline
\end{tabular}

Fucnte: SARMIENTO ANZOLA, Libardo (1996): "La Pobreza Rural en Colombia en el contexto latinoamericano". En Vanios, Una mirada social al campo. Santafé de Bogotá: Compilación de la Cumbre Social Rural, Ministerio de Agricultura, p. 52. 


\section{Cultivos proscritos}

Durante esta década en particular, la producción y comercialización de los cultivos ilícitos (marihuana, coca, amapola) han constituido uno de los factores más activos de conflicto en la sociedad colombiana. Han afectado las relaciones políticas a nivel nacional e internacional, la consistencia y eficacia de las instituciones, en concreto las referidas a la justicia y a la salvaguardia de la ley, la cohesión social, las relaciones económicas e, incluso, el patrimonio nacional de recursos naturales.

La producción y comercialización de psicotrópicos se ha desarrollado en espacios diferenciados: las áreas de frontera "interna" y "externa", esto es, en zonas marginales dentro de la frontera agrícola y en sus bordes externos, en donde se ha implantado su cultivo, procesamiento primario y etapas iniciales de comercialización; algunas áreas urbanas y semi-urbanas en donde se adelantan algunas fases de procesamiento y remisión hacia los mercados nacional e internacional. Esta "división espacial" de la narcoeconomía no es absoluta, en la medida en que sus prácticas técnicas han generado conocimientos en el nivel de los productores que les permite avanzar en la cadena de comercialización, hasta el punto de convertirse, algunas de estas regiones, en exportadoras directas.

La dimensión de estas actividades dentro de la economía nacional ha sido objeto de diversos análisis, de los cuales los adelantados por Francisco Thoumi (1994) pueden ser considerados como los de mayor profundidad. Esta calificación radica en el esfuerzo de este investigador por establecer las articulaciones entre el desarrollo de la narcoeconomía y los componentes económicos, políticos, sociales e ideológicos-culturales de la sociedad colombiana.

La aproximación "multilateral" al fenómeno de la narcoeconomía permite incorporar varios aspectos a su explicación: de un lado, el atraso secular en las formas de explotación de la tierra y, por ende, de las relaciones de producción que se generan; de otro, los niveles de concentración de la tierra: para 1989, el $67 \%$ de los propietarios poseía el 5.2\% de la superficie, mientras que el $1.3 \%$ de ellas cubrían el 48\% del área (Mondragón, 1997: 167). A ello se agrega, en lo material, una difícil integración nacional resultante de la pobre red vial existente en el país, la cual, en su trazado, poco se aparta de los que fueron caminos reales en la época colonial. Desde el punto de vista político y cultural, alimenta a este fenómeno la tradición contrabandista, internalizada tanto en las élites nacionales como en otros sectores de la población (recuérdese al respecto, el manejo del comercio en las sociedades de la costa Caribe durante el período colonial y luego de él, el contrabando de ganado, café y esmeraldas, las "fugas" de capitales, etc.).

A los factores anteriores se añaden la debilidad generalizada del Estado, más evidente en ciertas regiones, el uso común de las armas como vía privada y pública para la supuesta resolución de conflictos, las fragilidades éticas y políticas derivadas de la ausencia de un proyecto nacional articulador de la sociedad y, todo ello, en un contexto geográfico altamente favorable a la implantación de actividades ilícitas particularmente rentables.
Estos elementos han tenido escenario privilegiado en las regiones en donde inicialmente se manifestó el fenómeno, en torno a la producción y comercialización de la marihuana (Costa Atlántica) y, luego, en otras regiones en donde se fueron articulando sectores sociales con proyectos similares. Así, las bandas armadas de contrabandistas de esmeraldas se incorporaron a la producción de marihuana y la implantaron en zonas de colonización ocupadas por coterráneos, parientes o amigos, con quienes establecieron los vínculos necesarios para impulsar los cultivos y el tráfico de sus productos. El camino de la marihuana a la coca lo señaló el mercado y las trochas de la colonización fueron ampliando los espacios de la producción.

La apropiación violenta de las cosechas, en el caso de la marihuana y después de la coca por parte de las bandas de traficantes o agentes del Estado vinculados a ellos, dio campo al ingreso de la guerrilla como nuevo interlocutor, dispuesto a favorecer a los pequeños y medianos cultivadores, su base política natural.

El ingreso de la guerrilla significó, también, la incorporación de un nuevo participante en el ciclo de la comercialización, con el cobro del "impuesto de guerra" que ella estableció sobre los compradores y que implicó una reducción en los márgenes de ganancia de los traficantes. Estos, en no pocas oportunidades, prefirieron asociar a representantes de las autoridades policíacas o militares a sus empresas, comprometiéndolas en campañas antisubversivas o de "erradicación" dirigidas de cultivos, a fin de evitarse el impuesto de la guerrilla.

La dinámica que agregan estos componentes al problema de la narcoeconomía en Colombia le generan un perfil propio y un nuevo papel en el tráfico a nivel mundial. De una parte, la producción de hoja de coca, de amapola y procesados se mantiene a pesar de las fumigaciones y otras medidas de fuerza tomadas por el Gobierno contra los cultivadores, comerciantes y algunos narcotraficantes. De otra parte, los cambios en la política norteamericana, en la cual se dio un viraje desde los primeros días de la administración Clinton, cuando descendió el "perfil militar" de la política antinarcóticos, hasta la desmesurada presión contra Colombia como país productor e intermediario, en la etapa subsiguiente al triunfo electoral del partido republicano y los desarrollos subsiguientes de esta posición.

La situación creada en el área de las relaciones internacionales del país, en particular con los Estados Unidos, ha tenido ya repercusiones en el conjunto de la sociedad y la economía colombianas, dada la importancia que los recursos derivados de la narcoeconomía tienen en el conjunto de la vida nacional. Así, en los primeros días de 1996, la decisión del gobierno de fumigar los cultivos de ilícitos provocó movilizaciones importantes en el Guaviare, Putumayo y Caquetá, con posibilidades de extenderse a otras zonas de producción. Adicionalmente, la presencia de la insurgencia armada en el complejo de la narcoeconomía, por el efecto de las relaciones ya señaladas y en un contexto político dentro del cual ha recuperado su importancia la búsqueda de una paz negociada, configura un factor crítico para las perspectivas de un manejo "desnarcotizado" del desarrollo del país y de sus relaciones internacionales. 
Teniendo en cuenta lo anterior y el significado de estos procesos para las áreas de frontera, se examinarán, a continuación, las condiciones que ofrecen actualmente estas regiones desde la perspectiva de los cultivos ilícitos.

El panorama de las áreas productoras ha tenido modificaciones muy importantes desde finales de los 80 hasta ahora. El cambio más notable ha sido el desarrollo del cultivo de amapola, el cual, a diferencia de la marihuana y la coca, se ha implantado en zonas características del interior de la frontera agrícola, principalmente en el centro del departamento de Nariño, Cauca, sur del Tolima. Los cultivos de coca han continuado en las "áreas de frontera", en donde se localizaron prácticamente desde el principio de su ciclo, esto es, los departamentos de Guaviare, Putumayo y Caquetá, principalmente. La marihuana, luego de su desvanecimiento a inicios de los 80 , ha reaparecido recientemente y de manera particularizada en la Sierra Nevada de Santa Marta y el sur del departamento de la Guajira, como resultado de la ampliación de la demanda de derivados de esta planta.

La comercialización del látex extraído de la amapola ofrece, a los productores, ingresos incomparablemente más elevados que los obtenidos en sus cultivos tradicionales como el maíz y el fique: hacia la mitad de 1992, el precio del kilo de látex tenía un precio que oscilaba entre US $\$ 1.000$ y US\$ 1.500; a su vez, los jornales pagados estaban en US\$1,5 diarios, en tanto que, en los cultivos tradicionales, el pago era de US\$0,8.

El surgimiento de esta actividad ha incidido en la mayor dinamización de las relaciones económicas en el interior de las zonas productoras y entre éstas y otros espacios. Así, además del atractivo de los salarios, altamente competitivos con los pagados en los cultivos tradicionales, la producción de amapola ha atraído a los campesinos y jornaleros previamente ocupados en los cocales, debido a las diferencias en los precios, y ello también ha ampliado el impacto de estos cultivos en los suelos y demás recursos naturales.

La información disponible sobre la producción de amapola y sus alcances económicos es poca y confusa: las cifras sobre áreas sembradas ofrecen oscilaciones que quitan credibilidad a cualquiera de las versiones'. Con certeza se puede decir que han tenido una expansión, frente a la cual, las acciones de erradicación parecen tener muy pobres resultados. Igualmente, a pesar de los bandazos, los precios de la pasta de coca y de la goma de la amapola, siempre se sitúan por encima de los de cualquiera de los renglones tradicionales de las economías campesinas, condición digna de tenerse en cuenta en un contexto de competencia de productos importados de más bajo costo. En este mismo sentido, también vale tener en cuenta procesos como el actual desmantelamiento de la producción cafetera, sin sustitutos viables económicamente y ocurridas en áreas contiguas a las potenciales de producción de amapola.

En términos generales y como se ha sostenido en los análisis más realistas, el afianzamiento de los cultivos ilegales pone totalmente en duda la eficacia de las distintas acciones encaminadas a su erradicación aplicadas hasta ahora. En ello incide lo ya observado con respecto a los precios comparados con la producción campesina tradicional, así como otros factores, analizados por los especialistas: la corrupción de las autoridades en los distintos niveles, la insuficiencia de los recursos aplicados, tanto por el Estado como por las agencias internacionales participantes en las políticas de sustitución de cultivos, y las dificultades propias de la cooperación interinstitucional dentro de esquemas imprecisos en cuanto a competencias de las entidades internacionales.

Las perspectivas futuras de los cultivos ilegales no son claras. De lo anterior se desprenden dos observaciones preliminares: la población ligada a su producción, como campesinos o jornaleros, ven en ellos una oportunidad única de obtener o mejorar ingresos, dentro de un marco económico permanentemente deprimido. En segundo lugar, la identificación y prácticas de producciones alternativas, en gran medida, es cuestión de precios, de competitividad dentro de un contexto de mercados cada vez mas abiertos, lo cual implica la intervención de políticas de reciprocidad hacia los mercados que, de una u otra manera, inciden o pueden incidir en la producción de las regiones en donde se implantan los cultivos proscritos.

La debilidad del Estado colombiano, en términos de recursos fiscales y medios técnicos, de capacidades para la coordinación de las distintas agencias que lo componen y de capital humano, se manifiesta no solamente en la baja o nula disponibilidad de infraestructuras en buena parte de las regiones, sino también en la pérdida creciente de su legitimidad en varios espacios del país. Ocurre así, entonces, que el Estado pierde, de manera sostenida, la capacidad de controlar su propio territorio, generando en sus bordes externos, y también en no pocos espacios internos, fragmentos de una sociedad marginada y empobrecida, desplazada hacia ellos por la inexistencia de políticas incluyentes de desarrollo económico y social que les hubiese permitido el acceso a la tierra, a mercados de trabajo y a los servicios del Estado, así fuesen precarios.

La más compleja expresión regional de esta situación ocurre en la Amazonia colombiana, principal escenario de la producción de hoja de coca, el más importante de los cultivos ilícitos. Se trata de un territorio que abarca el $36 \%$ del total del país, como consecuencia de las emigraciones forzadas de motivación económica o política se ha configurado un conglomerado humano de cerca de 700.000 personas, ubicado en espacios de muy limitado potencial productivo, al menos dentro de las condiciones actuales de nuestro desarrollo tecnológico. La desequilibrada articulación de sus economías a los mercados regionales y nacionales y su marginalización con respecto a la oferta y a la gestión de los servicios públicos han facilitado el arraigo de la producción y comercialización de los cultivos ilícitos y de la actividad subversiva de las guerrillas, sin que ni el Estado ni la sociedad colombiana hayan logrado configurar un proyecto estable, de largo plazo, de incorporación efectiva de este espacio a la territorialidad nacional.

Como se ha señalado, la coyuntura que vive el país al acercarse el final de este milenio ha agudizado los efectos acumulados de las políticas excluyentes en cuanto a la dis-

1. Ver a este respecto, URIBE, S. (1997): "Los cultivos ilícitos en Colombia". En Thoumi, F. et al. 
tribución del ingreso, el acceso a la tierra, a los factores productivos, a los servicios públicos y a la participación política. La transición hacia un nuevo modelo económico ha generado dificultades para la producción agropecuaria y sus mercados laborales, con lo cual se ha ampliado la economía de los cultivos ilícitos, fortalecido los procesos de concentración de la propiedad en manos de grandes narcotraficantes y extendido la pérdida de gobernabilidad. A estos factores se añaden las presiones externas, las cuales tienen manifestaciones incluso en tensiones fronterizas que hacen aún mas patente la baja capacidad de la sociedad colom biana y de sus instituciones para preservar la propia seguridad territorial.

De esta manera, la confrontación con la narcoeconomía y los problemas asociados y derivados de ella conduce al país, de forma insoslayable, a un replanteamiento de sus políticas de desarrollo territorial, económico, social y militar; se convierte en un problema de carácter estratégico nacional. En efecto, y si bien la producción de los cultivos para fines ilícitos se ha extendido a numerosos municipios de todo el país, por las características económicas, políticas, sociales, ambientales y militares que este problema ha asumido en la Amazonia, amerita un tratamiento prioritario.

Diversas opiniones coinciden en reconocer la baja capacidad de los suelos amazónicos para sustentar asentamientos humanos soportados por las tecnologías corrientes de explotación agrícola y pecuaria. Sus producciones y productividades, consideradas por distintos especialistas, apuntan a priorizar, de manera exclusiva, la permanencia de núcleos de población limitados en su tamaño y orientados en sus actividades productivas a aquellas de preservación del bosque y explotación regulada de sus recursos.

Consecuentemente, la mayor parte de los asentamientos existentes en la actualidad se han hecho viables únicamente por el desarrollo de la narcoeconomía, con todas sus consecuencias. Por esta razón, la decisión de la sociedad colombiana y de su Estado de erradicar estas actividades ha de comprender, dentro de la búsqueda de alternativas de vida dignas para estas poblaciones, su acceso ordenado a espacios para su reasentamiento, efectivamente adecuados para la producción, la transformación y la comercialización de productos agrícolas y pecuarios. Esta misma decisión implica romper la tradición colombiana de resolver los problemas agrarios derivados de la concentración de la propiedad territorial desplazando a los pequeños campesinos y trabajadores sin tierra hacia las fronteras agrarias, en las cuales no solamente se reproduce y amplía la pobreza sino también los problemas ya mencionados y conducentes a la ingobernabilidad. Se trata de iniciar el roll back de estos patrones de asentamiento precario y proceder a una ocupación racional del interior de la frontera agraria del país.

De esta manera, las soluciones para los problemas de nuestros asentamientos humanos en el bosque húmedo tropical, en particular en la Amazonia, difícilmente pueden encontrarse en ellos, al menos por ahora, y habrá que localizarlos en los territorios del interior (incluyendo la Orinoquia), los cuales ofrecen mayores posibilidades de sostenibilidad y articulación con los mercados regionales y nacionales.
El tema de los reasentamientos de poblaciones actualmente ubicadas en ecosistemas frágiles y de bajo potencial productivo es particularmente crítico, por cuanto la decisión de estos núcleos humanos de ocupar estos espacios no obedeció a razón distinta de la búsqueda de un refugio para defender la vida, reconstruir las economías y los vínculos sociales destruidos en los lugares de origen por la violencia política o económica. Les asisten, a estas poblaciones, sus derechos de preservar sus vínculos comunitarios y sus patrimonios productivos, lo cual, de hecho tiene espacios en las leyes vigentes y en las políticas de desarrollo; como lo son, concretamente, las Leyes 101 de 1993, sobre Desarrollo Agropecuario y Pesquero y 160 de 1994, la primera creadora del Incentivo a la Capitalización Rural y la segunda, marco del Sistema Nacional de Reforma Agraria, así como la política de Modernización Rural y Desarrollo Empresarial Campesino ${ }^{2}$.

Mediante la aplicación de estas leyes e instrumentos de política es posible iniciar la configuración de un desarrollo rural basado en la racionalización de la ocupación del espacio. Esta perspectiva, da pie a la recuperación de ecosistemas frágiles, actualmente ocupados en condiciones de plena precariedad social y ambiental, ofreciendo, a quienes hoy las ocupan, espacios atractivos para su desarrollo económico y social, pero excluyendo definitivamente el expediente de su expulsión violenta, el cual simplemente sería dinamizador de los conflictos actuales y, de ninguna manera, solución para ninguno de ellos.

Por otra parte, un replanteamiento de los patrones de ocupación del espacio con miras a la racionalización de su aprovechamiento presente y futuro, como expresión de una política territorial consistente, plantea para el Estado y sus instituciones, la posibilidad de asignar las capacidades defensivas de manera coherente con las priorizaciones estratégicas del territorio nacional.

\section{VIOLENCIA}

\section{La confrontación armada}

La ampliación de las confrontaciones bélicas en el país ha generado, entre otros efectos y como una reacción positiva, manifestaciones de distintos sectores de la sociedad dirigidas a renovar esfuerzos en la búsqueda de soluciones negociadas a la guerra, para llegar a una paz sostenible. Estas expresiones se producen cuando la extensión de los conflictos reduce espacialmente la gobernabilidad, debilita las instituciones y pone en riesgo la propia soberanía nacional.

Por otra parte, la expansión de los escenarios de los conflictos y su profundización los plantea, en la actualidad, de manera mucho más clara como competencias bélicas en torno a territorios, lo cual ha conducido a generalizar los desplazamientos de las poblaciones afectadas. Algunos estudios recientes hablan de un millón de personas expulsadas por causa de la violencia ejercida contra ellas durante los últimos 10 años (El Espectador, marzo 1997) y solamente en la

2. Documento CONPES, diciembre 1994 
semana del 23 de marzo ese este año fueron desalojadas siete mil personas del sur del Departamento de Bolívar.

Los desplazamientos por la violencia son un fenómeno de vieja data en Colombia. Durante los conflictos desarrollados entre fines de la década de 1940 y mediados de la de 1960 , una parte importante de las migraciones campo-ciudad fueron motivadas por la guerra civil desatada entonces; al mismo tiempo, la acelerada ampliación de la frontera agrícola producida a partir de los años sesenta fue dinamizada igualmente por la evicción forzada de habitantes de varias regiones del país. Sin embargo, los desplazamientos que ocurren en la actualidad han llamado la atención de la sociedad nacional y de entidades públicas y privadas de otros países por su magnitud, la cual está asociada, necesariamente, con el empobrecimiento de esta población (ver Cuadro 1), pérdidas en la producción y en los esfuerzos sociales representados en infraestructuras, desarrollo institucional y otras modalidades del patrimonio público y privado.

De otra parte, el asentamiento masivo de desplazados en nuevas localidades plantea nuevas exigencias en generación de empleo y financiación de vivienda y servicios en estos lugares, agravando las deficiencias preexistentes. Como lo señalan las cifras y diagnósticcs disponibles, la ampliación de las distintas manifestaciones de violencia ocurre tanto en ámbitos urbanos como rurales, pero la magnitud de la guerra puede apreciarse de manera más evidente en el campo. Al mismo tiempo, los conflictos que se expresan en los medios citadinos tienen su origen en procesos propios de estos medios, pero también resultan del traslado de conflictos rurales que ocurren hacia ellos.

\section{Raíces agrarias del conflicto armado}

Los sectores dirigentes del país y los planificadores de sus orientaciones, con algunos matices diferenciados, desde principio de la década de 1990, consideraron superados los problemas agrarios que se habían manifestado en las décadas anteriores. Dentro de la lógica de asignar los recursos según demandas activas configuraron patrones presupuestales que redujeron sensiblemente la inversión pública en el campo (Perfetti y Guerra, 1994), al tiempo que se aplicaron reducciones a la protección ejercida previamente sobre la producción agrícola. Este fenómeno no ocurrió de manera exclusiva en Colombia; ha tenido lugar de manera generalizada (Banco Mundial, 1997), pero en nuestro país ha tenido connotaciones particularmente críticas como agravante de conflictos ya existentes.

El ejercicio de políticas para la apertura comercial puso de relieve severos problemas estructurales del campo colombiano, entre ellos los asociados con la concentración de la propiedad rural. Frente a ella, la reforma agraria planteada desde 1961 resultó inocua (Machado, 1987, Binswanger et al. 1993, etc.) y, por el contrario, a través de masivas titulaciones de baldíos facilitó la replicación de los patrones latifundistas en las áreas en donde se expandió la frontera agrícola sin permitir, prácticamente como norma, la estabilización de las economías campesinas y su evolución empresarial, supuesto móvil, entonces como ahora, de las leyes de reforma agraria.
El desarrollo de la "narcoeconomía" y las estrategias de "lavado" de activos asociadas a ella, así como la práctica consuetudinaria de liquidar las organizaciones campesinas y opositores como mecanismo de hegemonización política, afianzaron las tendencias preexistentes de concentración de la propiedad territorial, particularmente en las áreas de reciente incorporación a la frontera agrícola, como puede advertirse en los datos proporcionados por la Encuesta Agropecuaria de 1995 (DANE, 1996). Estas tendencias han activado los conflictos de creciente magnitud reseñados anteriormente, frente a lo cual se plantea la urgencia de una propuesta de paz de largo alcance, concebida en términos de una política de Estado, trascendente de los límites de una administración.

$\mathrm{Al}$ advertir repetidamente los analistas el carácter estructural de los conflictos agrarios ${ }^{3}$ así como las profundas relaciones existentes entre éstos y el conjunto de la crisis nacional se plantea, de una parte, la necesidad de construir relaciones de equidad en el campo y se reconoce el papel de una reforma agraria efectiva para este propósito. Por otra parte, se sustenta igualmente, la relevancia central de la superación de los conflictos del campo, en particular los asociados con el reparto agrario y la modernización de sus estructuras productivas y políticas, para la solución de la crisis nacional.

\section{CONFLICTOS AMBIENTALES EN EL ORDENA- MIENTO DEL TERRITORIO}

A principios de la década de 1990 convergieron en el país las demandas promovidas por múltiples sectores internacionales (entidades ambientalistas estatales, organizaciones no gubernamentales, agencias financieras, etc.) con expresiones de origen igualmente variado, de carácter nacional, en torno a la necesidad de desarrollar una conciencia ambiental y de impulsar políticas y acciones encaminadas al manejo racional y sostenible de los recursos naturales. Esta convergencia, ocurrida prácticamente en todos los países, puso en evidencia la magnitud de la crisis ambiental colombiana, asociada con los patrones de consumo, la concentración de la propiedad de la tierra, la prevalencia de tecnologías depredadoras para el manejo de los suelos, las aguas, los bosques y todos los demás recursos renovables y no renovables. Puso también en evidencia las demandas de diferentes comunidades, sensibilizadas por el deterioro de su hábitat y conscientes de sus propias responsabilidades y de las correspondientes al Estado y al resto de la sociedad.

Este conjunto de manifestaciones logró expresarse en la Constitución y en la legislación ambiental derivada de ella, la cual contempla componentes políticos novedosos con respecto a la filosofía y al cuerpo de normas existentes con anterioridad. Sin embargo, la magnitud de los avances en la racionalización del manejo de los recursos naturales, en la responsabilización ciudadana en torno a esta gestión de los mismos y en resultados concretos en cuanto a la aplicación de estas normas ha sido particularmente magra.

3. Ver, Varios (1996): Una Mirada Social al Campo. Santafé de Bogotá: Compilación de la Cumbre Social Rural, Ministerio de Agricultura y Desarrollo Rural. 
La exposición de motivos de la Ley 99 de 1993 destaca la profundidad de la crisis ambiental que afronta el país, pero, más importante que ello, plantea con amplitud el significado estratégico de los recursos naturales, da cabida al concepto político de la participación de los ciudadanos en la toda la gestión pública, incluida la del medio ambiente, y reconoce el valor de la diversidad regional, cultural y biológica que caracteriza a la nación.

Estos elementos constitutivos de la Carta fundamental abren mayores posibilidades de eficacia a las normas ambientales, en la medida en que concilian las funciones del Estado con la realidad del país. Como se expone a continuación, la complejidad de las articulaciones entre la sociedad y su territorio es mayor que la de aquellas que ligan al Estado con la sociedad, en la medida en que las relaciones generadas en el proceso de ocupación del territorio traducen todas las particularidades de nuestro desarrollo histórico. En él han marcado su impronta: una gran heterogeneidad ecológica y cultural, economías débiles, sustentadas en ciclos de corta y mediana duración, frágiles desarrollos de la sociedad civil y un Estado caracterizado por muy bajas capacidades para proteger los espacios físicos y políticos del interés público.

Frente a estas condiciones, la búsqueda de un tipo de sociedad capaz de garantizar la sostenibilidad de su base ambiental hace indispensable el reconocimiento de las comunidades como agentes capaces de resolver, con el apoyo del Estado, la gestión de sus territorios y recursos productivos.

La existencia de normas y políticas ambientales, apoyadas en una conciencia creciente dentro de la sociedad, de la necesidad de un manejo racional de los recursos constituye una base apropiada para producir cambios significativos en este campo. A nivel de la producción agrícola y pecuaria se han ampliado las exigencias en el manejo ambiental y el aprestamiento de capacidades para atender este manejo. No obstante, el carácter estructural de los factores que inciden en esta crisis hacen muy lenta su modificación o remoción. Este es el caso de la concentración de la propiedad de la tierra, la cual, a la par que impide la ampliación de los espacios productivos a las economías minifundistas, genera mayores presiones sobre suelos sobreexplotados con tecnologías depredatorias y ha forzado el desplazamientos de las poblaciones "excedentes" hacia las fronteras agrarias, ya localizadas en áreas de bajo potencial productivo, en las cuales se han extendido los actuales procesos de colonización, tanto en las tierras bajas cálidas como en tierras altas marginales.

Estas colonizaciones, estimuladas, ya por la necesidad de encontrar posibilidades de resolver las urgencias económicas, ya por la necesidad de proteger la vida misma, no han encontrado en el Estado el interlocutor que requieren comunidades débiles y carentes de medios para afrontar la exigente empresa de construir nuevos asentamientos en medios adversos a las formas tradicionales de ocupación del espacio en nuestro país. El resultado ha sido la ampliación de la pobreza rural, el deterioro de extensos territorios de la frontera agrícola y la expansión de muchos de los conflictos que hoy caracterizan a la sociedad colombiana. (Fajardo et al., 1997).

El tema de las colonizaciones corresponde, esencialmente, a la ocupación del espacio y, más específicamente, al establecimiento, en áreas determinadas, de asentamientos con nuevos sistemas de poblamiento. Al hablar de "establecimiento" se hace referencia a un proceso de alguna duración temporal, durante el cual se desarrollan actividades dirigidas a posibilitar la subsistencia de una colectivo humano, en este caso, a partir del aprovechamiento de recursos disponibles en ese espacio. Tales actividades se cumplen a partir de la existencia efectiva de los recursos disponibles, cuyo aprovechamiento requiere el conocimiento de su existencia, sus atributos, formas de utilización y acceso a los mismos.

La ocupación de espacios dentro de esta dinámica tiene otras implicaciones. De una parte, resulta del desplazamiento de las poblaciones que acceden a los mismos a partir de sus lugares de origen, motivado por razones de distinta índole, como pueden ser el agotamiento de los recursos que garantizaban su existencia previamente, el crecimiento demográfico que desborda la capacidad de su espacio nativo para sustentar a los nuevos miembros o las presiones efectivas de otras comunidades para apropiar los recursos que sustentaban a la población original

Como es fácil comprenderlo, en Colombia el tema es de gran complejidad, dada la magnitud del territorio y las grandes heterogeneidades de nuestras estructuras agrarias. Sus alcances económicos, políticos y sociales, ligados a la búsqueda de soluciones para nuestro problema agrario, base de una paz duradera en el país, lo hacen merecedor de un tratamiento particular, que desborda, sin embargo, los límites de estas notas.

En este contexto, acompañado por la reconocida debilidad del Estado, es fácil comprender las tendencias demográficas de la ruralía colombiana, en donde se distingue, de una parte, la continuidad de las migraciones campo-ciudad en las áreas centrales del país y, de otra, la ampliación de los procesos colonizadores de las tierras bajas cálidas de los bosques húmedos (Amazonia, andén Pacífico, Valle medio del Magdalena, Urabá).

El afianzamiento de la concentración de la propiedad territorial rural ha ocurrido con fuerza particular en las tierras de mejor vocación agrícola y pecuaria, aun cuando no exclusivamente en ellas, como lo demuestra la Encuesta Agropecuaria mencionada. Al margen de estos espacios han quedado otros territorios (relictos de los páramos y el grueso de los bosques tropicales), los cuales, al tiempo que constituyen santuarios de biodiversidad, por la configuración de sus suelos y sus características climáticas, no ofrecen atractivos para la producción agrícola o pecuaria dentro de los patrones tecnológicos dominantes; se convierten así en las áreas marginales, propicias para el asentamiento de las poblaciones expulsadas del interior de la frontera agrícola, siguiendo tendencias claramente reconocidas a nivel mundial, de los procesos que han conducido a conflictos económicos y políticos derivados de la concentración de la propiedad rural y la exclusión de los pequeños campesinos del acceso a la tierra.

En otros términos, las colonizaciones campesinas tienden a dirigirse hacia espacios que, por sus características edafológicas y climáticas, han generado amplios contenidos de especies biológicas, al tiempo que presentan limitada potencialidad para las prácticas agrícolas y pecuarias dominantes. 
Confluyen en este cuadro dos grandes componentes de un ordenamiento territorial: de una parte, la valoración de los territorios y sus recursos, resultante de la difusión, en muchos sectores de la sociedad, de conocimientos y apreciaciones prácticamente universales, sobre la biodiversidad y la urgencia de su conservación. Por otra parte, el surgimiento de condiciones políticas que, eventualmente, pueden facilitar acuerdos entre los pobladores y el Estado en torno a la organización del territorio y al manejo de sus recursos.

\section{ECONOMÍA POLÍTICA DE LOS CONFLICTOS EN EL CAMPO COLOMBIANO}

\section{El Estado: su acción u omisión y los intereses "particulares"}

De tiempo atrás, el Estado colombiano ha demostrado una capacidad muy limitada para atender las demandas crecientes de la sociedad, en razón del autoritarismo del régimen político, de la debilidad fiscal, de su apropiación patrimonialista por parte de las dirigencias políticas y de su descomposición por efectos de la corrupción. Frente a esta incapacidad se han generado múltiples forma de protesta de las comunidades y, a instancias de la propia sociedad y de organismos internacionales, se han introducido importantes reformas en las estructuras políticas y administrativas de la nación, referidas a la municipalización de la gestión estatal y a la ampliación de la participación popular.

Los resultados de estas reformas ya se hacen sentir, tanto en el creciente volumen de recursos transferidos desde el nivel central hacia los municipios, como en los avances en la capacidad de gestión descentralizada. No obstante, la persistencia de los factores generadores de la crisis y la guerra inducida por éstos y otros factores han desbordado la capacidad de gobernar en variados aspectos de la vida nacional y en buena parte del territorio. Avances logrados por las reformas, como la elección popular de alcaldes y las veedurías populares, han resultado afectados por las manifestaciones de violencia que tienen en lo local su escenario natural.

El lento progreso de las políticas sociales y económicas dirigidas hacia el campo, marcadas por la discontinuidad de las administraciones del Estado, contrastan con la rápida expansión de los conflictos. Este tema de las "dos velocidades" (Fajardo, 1996) conviene tenerlo en cuenta al analizar su significado en la prospectiva del desarrollo nacional.

Hacemos mención a las "dos velocidades" que parecieran marcar la dinámica social, económica y política del país: los ritmos dispares de los conflictos de un lado y de las soluciones, de otro. A ello se añade la distancia creciente entre dos grandes sectores de la sociedad: uno, representado por un segmento urbano del país, articulado a componentes modernos de la economía y los servicios, con "representaciones culturales" propias de estos ámbitos. El otro, correspondiente a un extenso mundo rural, de pequeños y medianos campesinos, indígenas y trabajadores sin tierra, afectado por una marcada inequidad en su acceso a los beneficios de lo que, genéricamente, se podría denominar "el desarrollo", distribuido en un territorio caracterizado por una precaria presencia estatal.

En este contexto ha echado raíces el problema del narcotráfico, facilitando estrategias internacionales, movidas por intereses geopolíticos que presionan la misma seguridad fronteriza del país, al tiempo que cuestionan la legitimidad de las instituciones nacionales, debilitadas por efectos de los problemas ya señalados.

De esta manera, Colombia está experimentando los costos de la aplicación de políticas y decisiones que colocaron al campo un lugar secundario en cuanto a la asignación de recursos, el tratamiento de las poblaciones rurales y la solución de los problemas políticos, económicos y técnicos de su modernidad y modernización. La lógica que condujo a estas decisiones estuvo guiada por los cambio dramáticos que caracterizaron a los patrones de distribución espacial de la población a partir de la década de 1960 y por las tendencias en la configuración de la economía nacional, en la cual adquirieron creciente importancia los servicios y la manufactura, al tiempo que la construcción fue estimulada como "sector líder" en el desarrollo económico.

\section{Distribución de la propiedad agraria}

Indudablemente, en la percepción económica de la problemática agraria no ha gravitado el tema de las estructuras de la propiedad rural, pese a que la participación de los costos de la tierra representan, en promedio, un $11 \%$ de los costos totales de la producción (Gutterman, 1994) y a que el "narcolatifundio" comienza a restaurar los efectos de los patrones de concentración de la propiedad que parecían superados a finales de la década de 1970 según lo advertían los estudios sobre la propiedad rural entonces (CEGA, s.f.). A este respecto, algunos cálculos establecen entre un 7 y un $8 \%$ del total de la superficie agrícola del país, estimada en 40 millones de hectáreas, el porcentaje de tierras controladas por el narcolatifundio.

De esta manera, la distribución de la tierra no pareciera haber afectado la capacidad productiva de las economías agrarias, pero sin que ello la eliminara del debate político. En efecto, tanto la ley 30 de 1987, como la 160 de 1994 han guardado mayor correspondencia con la búsqueda de soluciones a los conflictos sociales del campo. Sin embargo, algunos análisis recientes de carácter preliminar, adelantados por especialistas del Banco Mundial en torno a la situación social del campo (López y Valdés, 1996) y al impacto de la violencia en el desempeño del sector (Bejarano, 1997a), factores con los cuales se asocia al reparto agrario, también inducen su examen a la luz de las consideraciones económicas.

Los siguientes datos ilustran el incremento de la concentración de la tierra. Para 1960, el 67\% de los propietarios con predios menores de 5 Has. ocupaba el $6 \%$ de la superficie, mientras que el $1.4 \%$ con propiedades mayores de 200 tenían el 46\%. Para 1984, el $0.37 \%$ de los propietarios poseedores de predios de más de 500 Has. poseía el $34.8 \%$ del total de la tierra en nuestro país y el tamaño promedio de los latifundios de más de mil hectáreas pasó de 2.764 Has. en 1970 a 3.562, mientras el 57\% de los propie- 
tarios, con parcelas de menos de 3 Has. tenía menos del 3\% de la superficie (CEGA s.f.). Para 1989, el 67\% de los propietarios poseía el $5.2 \%$ de la superficie, mientras que el $1.3 \%$ de ellas cubría el $48 \%$ del área. El coeficiente de concentración de Gini, pasó de 0.83 en 1961 a 0.87 en 1970 y 1984 (Heath, Deiningar, 1997).

Otro dato lo proporciona la Encuesta Nacional Agropecuaria del DANE (s.f.: 173); aun cuando no midió segmentos de muestra de más de 1.200 has. y por tanto no se pueden ver las propiedades que superan ese tamaño, ni calcular índices ciertos de concentración, permite elaborar el siguiente cuadro resumen:

\section{CUADRO 2}

Tamaño del segmento Has.

Muy Pequeño ( 0-5)

Pequeño (5-20)

Mediano (20-50)

Grande (50-200)

Muy Grande (200-1.200)

\begin{tabular}{c|c|c}
\hline Fincas & Tierra & Agrícola \\
$\%$ & $\%$ & $\%$ \\
46.8 & 3.2 & 38.6 \\
27.5 & 9.9 & 22.9 \\
12.8 & 13.8 & 12.7 \\
10.2 & 33.3 & 6.9 \\
2.8 & 39.9 & 2.5
\end{tabular}

El resultado sugiere que en 1995 se mantenía como característica estructural la alta concentración de la propiedad de la tierra, en realidad muy alta porque este tipo de encuesta no detecta varias propiedades en manos de una persona, ni las mayores fincas.

Por otra parte, aun cuando el estrato medio de tamaño de finca tiene la mayor cantidad de tierra utilizada para la agricultura (el $20.4 \%$ del total de las tierras de uso agrícola, con sólo el $12.8 \%$ del total de la tierra), dedica solamente el $12.7 \%$ de su superficie a este fin; en tanto que los más pequeños productores dedican el $38.6 \%$ de la superficie a la agricultura e inclusive dentro de ellos, los extremadamente pequeños dedican el $43.4 \%$ de sus parcelas a ese fin.

Las grandes fincas se destacan por la dedicación de la superficie a pastos y malezas, a la ganadería especialmente extensiva, en un $72.3 \%$, poseyendo un $2.8 \%$ de las fincas, donde está el $42.1 \%$ de las tierras ganaderas.

El trinomio ganaderos-gamonales-narcotraficantes es en la actualidad el polo de concertación de la contrareforma agraria que ocurre en Colombia. Los esquemas de colonización en nuestro país, como ya se ha señalado, se sostienen bajo la espontaneidad, debido a factores expulsivos de la población: violencia política y presión por la tierra, y a la falta casi absoluta de presencia del Estado.(Mondragón, 1997: 167-170).

En estos espacios se ha materializado un agudo conflicto armado con raíces históricas. Los oponentes en esta confrontación han podido alinear, por distintas razones, a la población rural y actúan dentro de escenarios de guerra cada vez mas extendidos, agravados por el narcotráfico y que, gradualmente, permean medios urbanos afectados por la marginalización propia del modelo de sociedad establecido.

En este punto conviene recordar al profesor Samuel Huntington (1968), cuyo pensamiento en torno a los desequilibrios campo-ciudad y los conflictos subsiguientes podrían sintetizarse así: “...el campo juega el papel de fiel de la balanza en el proceso de modernización política. Si el campo apoya el sistema político y no se enfrenta al gobierno, el sistema está seguro contra una revolución. Si el campo está en la oposición, tanto el sistema como el gobierno están en peligro de ser suplantados. El papel de la ciudad es, permanentemente, el de alimentar la oposición. El papel del campo es variable: lo mismo puede ser un puntal de estabilidad o la chispa de una revolución. La oposición del campo es fatal. Quien controla el campo controla el país".

Los analistas del conflicto armado en Colombia consideran con pesimismo las capacidades actuales de la sociedad colombiana y de su Estado para alcanzar una pronta solución a la confrontación (Bejarano, 1995; Rangel, 1996). Sin embargo, éstos y otros autores no desestiman los efectos positivos que en ese sentido tendría una política de Estado, de largo alcance y que trascienda las limitaciones de las iniciativas propias de cada administración, dirigida a incorporar al campo en un proyecto de desarrollo con democracia.

Dicha política de Estado cuenta con instrumentos jurídicos y de política que pueden ser aplicados en espacios geográficos estratégicos y con propósitos de impacto duradero en la organización económica, social y política del país.

Específicamente, es posible considerar la perspectiva de la Reforma Agraria dentro de los marcos del ordenamiento territorial y de la búsqueda de soluciones a los problemas que han dado lugar a los conflictos armados; considerarla dentro de las respuestas a la necesidad de construir un sistema de relaciones sociales, económicas y políticas inclusivo para todos los colombianos.

\section{El modelo de desarrollo en las leyes de Reforma Agraria}

Colombia tiene una larga tradición legislativa de reformas agrarias, acompañada de una ejecutoria sorprendentemente limitada de la misma. Esta tradición se inicia con la Ley 200 de 1936, con la cual se creó la Jurisdicción Agraria, a la cual se incorporaron jueces especializados en dirimir conflictos de tierras y se introdujo la figura de la Extinción del Dominio o pérdida de la propiedad como resultado del incumplimiento de su función social, cuando el propietario deja sin explotación económica la tierra durante un lapso determinado. Se reconoce, a esta Ley, el haber creado las bases del concepto de Reforma Agraria en la Colombia contemporánea.

La Ley 200 de 1936, como cualquier otro hecho jurídico, expresó una determinada correlación de fuerzas políticas ante un fenómeno determinado, en este caso, el problema del acceso a la tierra y las relaciones de trabajo asociadas a él. Pocos años más tarde, las condiciones políticas que condujeron a dicha Ley de tierras se modificaron sustancialmente y dieron paso, en 1944, a la Ley 100, la cual apuntó a neutralizar los posibles efectos de la aplicación de la Ley anterior, restituyendo los contratos de aparcería, como una de las formas más notorias de sujeción del campesino sin tierra a la propiedad terrateniente y de aislamiento de dicha mano de obra y de sus productos con respecto a los mercados, como lo han sintetizado Binswanger et al. (1993) en su análisis sobre las formas históricas de concentración de la propiedad territorial.

El profundo deterioro social resultante de la violencia de los años cincuenta y las presiones del gobierno norteamericano para evitar las influencias de la revolución cubana condujeron a la expedición de la Ley 135 de 1961, mediante 
la cual se reglamentó una "Reforma Social Agraria", dirigida a presionar a los grandes propietarios del agro a modernizar las explotaciones en su poder y permitir un uso más adecuado de sus suelos. Su lenta aplicación, contrastada con las grandes expectativas que generó, trató de remediarse con la Ley $1 .^{\text {a }}$ de 1968, la cual enfatizó la afectación de los predios inadecuadamente explotados, la entrega de la tierra a los aparceros que la estuviesen trabajando y facilitó algunos trámites. Según los analistas, logró provocar la baja del precio y de la renta de la tierra.

Esta ley se complementó con el estímulo a la organización campesina pero su impulso fue frenado en 1973 con el "pacto de Chicoral", acuerdo político entre los partidos tradicionales y los gremios de propietarios con el cual se puso fin a los precarios intentos del reformismo agrario. En adelante, se privilegió el estímulo al aprovechamiento más productivo de las tierras mediante la tenue presión de "mínimos de productividad" que nunca llegaron a operar; complementariamente, fue luego expedida una nueva ley de Aparcería (Ley 6. ${ }^{a}$ de 1975), con la cual esta relación fue relegitimada, luego de haber sido proscrita en la legislación agraria previa, asimilándola ahora a sociedad de hecho.

De esta ley en adelante, la legislación agraria se orientó hacia la adquisición de tierras por parte del Instituto Colombiano de la Reforma Agraria, Incora, la regulación de las colonizaciones y los programas remediales encaminados a resolver los problemas generados por la desordenada ocupación de las fronteras, como lo han sido el Plan Nacional de Rehabilitación (PNR) y los posteriores programas para la erradicación de cultivos ilícitos. La Ley 35 de 1982 reactivó la compra de tierras por el Incora, actividad que ha estado signada por notorios fenómenos de corrupción: con las mediaciones de los poderes políticos regionales se ha inducido la adquisición de predios de muy baja calidad, a precios colocados muy por encima de su valor productivo, para ser luego transferidos a los supuestos beneficiarios.

Esta práctica ha inducido nuevos problemas de cartera para las agencias de crédito, en particular para la Caja Agraria, dada la muy baja factibilidad de los proyectos productivos emprendidos por los campesinos cubiertos por la acción del Incora, los cuales han sido ubicados en tierras de baja calidad, con recursos de crédito costosos e insuficientes, carentes de asistencia técnica adecuada y con dificultades severas en el acceso a los mercados.

La aplicación de la Ley 35 de 1982 aceleró la adquisición de tierras por parte del Incora; las cifras disponibles registran cómo de 4.400 hectáreas adquiridas en 1981, se pasó a 25.111 en 1985, 54.704 en 1987, cifra no superada desde 1971, cuando se habían adquirido 73.183 hectáreas, para llegar a 96.098 en 1992 (Mondragón, op. cit.), tendencia explicable por los incentivos que muchos terratenientes, deseosos de vender predios improductivos, y altos funcionarios encontraban en las transacciones.

La gradual eliminación de la acción expropiatoria condujo, a través de la Ley 35 de 1982 y de la 30 de 1988, a introducir la figura de "reforma agraria vía mercado de tierras", que aparecía más grata y menos conflictiva a los propietarios y a los sectores políticos afines a ellos y que fue explícitamente incorporada luego en la Ley 160 de 1994.
Esta Ley se enmarca en el proyecto neoliberal de reducción del Estado y cesión al mercado de las funciones que le eran propias al primero. Propone una redistribución de la tierra basada en la menor intervención del Estado en las negociaciones, buscando la dinamización del mercado de las tierras otorgando subsidios a través de un programa redistributivo con énfasis en el acceso individual del campesino a la tierra.

La Ley 160 de 1994 fue promovida y aprobada en el contexto de una política de apertura a los mercados internacionales; dentro de ella, una intervención de esta naturaleza en el reparto agrario parecería contradictoria con la teoría que guía a las políticas aperturistas, caracterizada por su propuesta de tratamiento "no discriminatorio" a los distintos sectores de la economía y opuesta, por tanto, a intervenciones estatales en el juego económico -al menos teóricamente-. Sin embargo, de acuerdo con el diagnóstico mencionado sobre los efectos de la concentración de la propiedad en los costos de la producción, una acción redistributiva tendría un impacto favorable para la competitividad de los bienes de origen agropecuario.

Por otra parte, el contexto económico y político nacional condiciona, necesariamente, los alcances de la intervención en el reparto agrario. En este sentido, se comprende la estrategia de la "redistribución por la vía del mercado", la cual limita la participación directa del Estado en la configuración de la estructura de la propiedad. Esta participación se circunscribe, dentro del marco de la operación del mercado de tierras, a la asignación de un subsidio equivalente al $70 \%$ del valor del predio negociado, a favor de los beneficiarios, así como al suministro de servicios y su coordinación para atender las áreas de reforma agraria y los productores involucrados.

El programa oficial de Reforma Agraria a 16 años, propuesto para la aplicación de esta ley, pretende cubrir un total de 721 mil familias carentes de tierra, para lo cual se requeriría comprar más de 4.5 millones de hectáreas y realizar inversiones superiores a $\$ 3$ billones de pesos (de 1994). Para el período 1994-1998, se propuso atender a 250 mil familias ( $15 \%$ de la población objetivo) con un área de 6 millones de hectáreas e inversiones de $\$ 671.500$ millones, lo cual, dada la profunda crisis fiscal desatada desde 1996, simplemente no se cumplió.

En efecto, el Incora, como las demás entidades del Estado comenzó a afrontar severos problemas financieros desde 1995: en ese año, de 69.797 millones de pesos programados para inversión, se ejecutaron 51.903 , equivalentes al $74 \%$ y de 120.624 hectáreas por adquirir, solamente se concretaron poco más de 55 mil, el $45.7 \%$, porcentaje muy inferior al de inversión ejecutado, debido al alto precio pagado por las tierras. Por esta razón, de 9.700 familias beneficiarias previstas, únicamente 4.900 , el $51 \%$ de las programadas, se beneficiaron con las tierras adquiridas ese año.

Siguiendo a Antonio García $(1970,1982)$, puede afirmarse que la Reforma Agraria en Colombia ha tenido carácter marginal: se ha tratado de una reforma dirigida a mantener el status quo del complejo "latifundio-minifundio", con concesiones a la mediana propiedad, a través de la canalización de las presiones sobre la tierra hacia las fronteras 
agrarias, privilegiando la titulación de baldíos y afectando las tierras del interior solamente de manera lateral cuando lo ha exigido la confrontación social.

Este carácter marginal de la reforma agraria colombiana se expresa en la magnitud de las superficies intervenidas y en la modalidad de la intervención: hasta 1996, el Incora había adquirido poco más de 1.300 .000 hectáreas, el 4.71\% de las 28.300.000 que, según el IGAC, son aptas para labores agropecuarias, equivalentes al 3\% del área actualmente explotada. De la superficie adquirida, únicamente 69.000, el $5.6 \%$, fueron expropiadas; las restantes fueron negociadas directamente con los propietarios.

De no modificarse la voluntad política que hasta el presente ha alimentado el proceso, sin modificarse el número de familias carentes de tierra y si el Incora les adjudicara parcelas al ritmo anual promedio que ha tenido hasta ahora, las metas se cumplirían en 110 años, o 43 al ritmo del 1995. No obstante, esta estimación es irreal por cuanto no tiene en cuenta el aumento del número de familias sin tierra como resultado de las quiebras y embargos connaturales del capitalismo, así como, también, los desplazamientos causados por la guerra.

Aparte de las observaciones anteriores, la ley 160 de 1994 amerita otras consideraciones. En efecto, dentro del contexto de la Ley 160/94, se ha dado cabida a una figura novedosa: las "zonas de reserva campesina". Dirigidas a estabilizar los asentamientos de pequeños productores, con restricciones para la venta de los predios a fin de neutralizar la concentración de la propiedad y de afianzar modalidades productivas ambientalmente sostenibles, han generado discusión dentro de distintos sectores, pues, en tanto que para algunos solamente son aplicables en "áreas de colonización" (baldíos objeto de programas estatales de titulación), para otros, han de configurarse en espacios dentro de la frontera agrícola, con acceso a los mercados y a potenciales desarrollos agroindustriales.

El resultado de esta acción múltiple correspondería al proceso de "dotación de poder" (empowerment) a estas comunidades campesinas, en términos según los cuales, el equipamiento y mejoramiento de la infraestructura física y social estaría dirigido al propósito de "acceder a una parte mayor del excedente que genera la economía en su crecimiento" y exigiría una mirada amplia del entorno, centrada más en la región y menos en la finca o los proyectos productivos particulares (Moscardi, 1996).

Esta última alternativa, la más deseable desde el punto de vista del desarrollo económico y social del campesinado, plantea el interrogante de cómo hacer efectivo el control a la concentración de la propiedad en su interior. Por otra parte, solamente en la medida en que se configure un nuevo escenario político, favorable a una democratización efectiva de la economía agraria, que facilite la generalización de modalidades de proyectos productivos regionales con articulación efectiva a los mercados en el interior de la frontera agrícola, a través de la combinación del mercado de tierras y las zonas de reserva campesina, puede vislumbrarse la posibilidad de estabilizar a las poblaciones que continúan desplazándose hacia los bordes de la frontera agrícola, con los efectos ya advertidos.

\section{ECONOMÍA Y POLÍTICA}

La economía colombiana, al igual que la de otros países en condiciones de desarrollo similares, atestigua un descenso sostenido de la participación en ella del sector agropecuario. No obstante, es innegable el peso de la agricultura como conjunto de actividades agrícolas, pecuarias, forestales y de explotación de los recursos naturales en el conjunto de la sociedad nacional, por sus aportes a la oferta alimentaria, la heterogeneidad de su espectro productivo y su capacidad de absorción tecnológica, así como, también, por las dimensiones demográficas, sociales y políticas de su población.

La agricultura colombiana y el sector rural en general, han escenificado una rápida y profunda transformación en los últimos veinte años, como consecuencia de la acción de factores internos y externos. No obstante, la insularidad que ha caracterizado al país, las corrientes mundiales de la economía, la ciencia y la tecnología han proyectado sus influencias en Colombia. Estas dinámicas externas e internas dieron acogida a la "revolución verde", introduciendo cambios sustanciales en la producción y en la vinculación de la población a ella, generando una sostenida reasignación sectorial de la oferta laboral, su desplazamiento hacia los bordes de la frontera agraria, así como la relocalización de actividades productivas.

Una visión simplificada del agro colombiano podría imaginar su rápida homogeneización, por efecto de la apertura y de la internacionalización de la economía. No obstante, y según lo visto, los impactos de este proceso son múltiples y diferenciados según las regiones, los tipos de productos y las condiciones de sus articulaciones con los mercados. Previsiblemente, algunas regiones pueden asumir rápidas transformaciones en su organización productiva, en tanto que otras podrían distanciarse en su desarrollo, dando cabida a procesos de mayor deterioro social y ampliación de los conflictos existentes.

Las condiciones socioeconómicas de la población rural ofrecen tres características: de una parte, y como ya lo anotamos, la persistencia de condiciones de pobreza, las cuales afectan aún a más del $70 \%$ de los hogares, con variaciones regionales. De otra, es perceptible la tendencia hacia la disminución de hogares y personas en situación de indigencia ("pobreza crítica") desde donde se han desplazado hacia el nivel de pobreza no crítica, la cual muestra incrementos en el período. Finalmente, y teniendo en cuenta la incidencia del gasto público en los niveles mas bajos de la distribución del ingreso, es claro que las restricciones en las asignaciones presupuestales impiden la disminución de los niveles registrados de pobreza.

La pobreza rural y el desarrollo de los cultivos ilícitos se han aunado con la deficiente oferta tecnológica para generar un extendido arrasamiento de los recursos naturales, incluyendo los suelos, aguas, bosques y recursos de fauna. Esta situación se ha generalizado en la frontera agrícola y se extiende a todas las áreas de colonización.

\section{El modelo de desarrollo y su significado en la organización del espacio}

Según lo expresado en torno al ordenamiento territorial-ambiental, en la medida en que una sociedad conoce su 
espacio y sus recursos y los valora de acuerdo con sus necesidades del corto, mediano y largo plazo, establece una organización para el uso y destino de cada uno de los componentes de su territorio. Esta organización del espacio traduce, como lo hemos visto, no solamente los conocimientos disponibles sino también, y de manera determinante, las relaciones de poder que estructuran a esa sociedad. Puede existir una elevada valoración de un espacio en términos de su significado ambiental, pero si la sociedad respectiva no tiene condiciones políticas para preservarlo, difícilmente puede haber coherencia en las acciones que incidan en su preservación o destrucción: "Un grupo social que no tiene el poder y la capacidad para comandar sus relaciones sociales no tiene tampoco el poder y la capacidad para ordenar sus relaciones con el medio natural" (Domínguez, 1992: 67).

En Colombia, dadas las características de su desarrollo histórico, económico y político, la ocupación del territorio no ha traducido un proyecto estratégico de largo alcance. Ha sido más el resultado de las formas de apropiación privada del territorio, derivadas, en un principio, de la administración colonial española y, posteriormente, del enajenamiento que hiciera el débil Estado republicano a favor de los sectores más poderosos de la sociedad de entonces (Le Grand, 1988). En esta secuencia han incidido de manera determinante $y$, prácticamente desde sus principios, los mercados externos: durante el período colonial español, la búsqueda de los veneros auríferos y de las minas de plata configuró buena parte de los distritos de la administración territorial (Colmenares, 1988). Luego del agotamiento de este recurso ocurrieron los ciclos de las quinas, el añil, el tabaco, la ganadería (en la Costa Atlántica), el café, el caucho, la tagua, las pieles y finalmente los "cultivos ilícitos", como dinamizadores de las sucesivas ampliaciones de la frontera agrícola.

En la retaguardia de esta dinámica han actuado, a su vez, los patrones históricos de tenencia de la tierra, así como también los efectos del modelo de desarrollo acogido por las dirigencias nacionales, basado en una alianza política entre terratenientes y elites financieras, uno de cuyos resultados más costosos para el desarrollo del país ha sido la consolidación del monopolio de la propiedad agraria.

A su vez, esta tendencia se ha conjugado con un modesto desarrollo productivo, centrado fundamentalmente en la mediana y pequeña propiedad (MESA, 1989). Así, las condiciones de la política macroeconómica para la producción agrícola y pecuaria, en particular, las tasas de interés y cambiarias, y en conjunto, la sobreprotección brindada por el Estado al sector financiero, han confluido con la concentración de la propiedad y las consiguientes rentas monopólicas de la tierra, para generar una agricultura no competitiva, desligada de sistemas eficientes de procesamiento agroindustrial y comercialización.

Con ello, las posibilidades de reasignación a otros sectores productivos de la población expulsada del campo por la concentración de la propiedad y por las formas de violencia asociadas a ella (de lo cual dicen mucho las cifras actuales sobre desplazados del campo por los conflictos armados), tal como lo recomendara Lauchlin Currie a comienzos de los años cincuenta, se han hecho particularmente limitadas y traumáticas. El resultado ha sido el incremento de la informalidad y la pobreza urbana, dentro de un panorama de extendido desempleo de carácter estructural.

\section{TAREAS DE LA SOCIEDAD FRENTE AL CAMPO: EL FORTALECIMIENTO DE LAS SOCIEDADES RURALES EN LA BÚSQUEDA DE UNA PAZ DURADERA}

La profundización del conflicto social y político del país parece haberse ubicado en el "punto de no regreso" desde hace ya algunos años; más aún, ha llegado a afectar el escenario de las relaciones internacionales de Colombia. Por otra parte, su profundización recibe la influencia tanto de factores externos como de los factores internos y los dos niveles deberán ser comprendidos dentro de las estrategias que el país habrá de diseñar y abordar para la superación de la crisis.

Las tendencias hacia la globalización de la economía y la apertura económica muestran, hoy en día, algunos de sus límites. Las economías centrales han sostenido sus políticas proteccionistas con algunas flexibilizaciones y muestran disposición a aumentarlas, pero también a aceptar la utilización de instrumentos de comercio internacional que abran márgenes de favorabilidad a los países periféricos. Por otra parte, dentro de estos últimos se ha ampliado la comprensión sobre la gradualidad de los procesos de apertura, las privatizaciones encuentran límites políticos y se abre camino la aceptación de algunos márgenes de intervención del Estado, todo como parte de las confrontaciones políticas resultantes de los efectos de los procesos de acelerada apertura y desmonte del Estado que tuvieron lugar a comienzos de la década.

Esta fase de replanteamientos hace posible que se afiance, se haga más explícita y consistente la posición de Colombia en cuanto a la definición de campos y límites precisos de la intervención del Estado, que hasta ahora le han dado al país un perfil propio, al menos en la región, como lo atestigua un estudio reciente comparativo de los países de la Junta del Acuerdo de Cartagena (Bejarano, 1997b) dentro de los cuales Colombia ocupa una posición intermedia entre el intervencionismo (Venezuela) y la desestatización (Bolivia).

Bajo esta perspectiva, Colombia puede madurar su experiencia de una prolongada aplicación de políticas proteccionistas abruptamente suspendidas por el ciclo aperturista, para ajustar una opción propia en la que combine la exposición a los mercados para aquellos renglones que no ameritan protección y defensa de aquellos renglones que, por consideraciones políticas, económicas y sociales si deban recibirla. En el caso de la agricultura, se trata de aquellos que sustentan las economías campesinas y los sectores con mayor capacidad de generación de empleo y más amplias posibilidades de aprovechamiento sostenible de los recursos naturales.

Esta política, guiada por el interés nacional de crear condiciones de convivencia y paz, no puede constituir una propuesta de protección a ultranza de sectores no sostenibles en términos sociales, económicos y ambientales: renglones 
productivos soportados en la concentración excluyente de la propiedad territorial y en tecnologías depredatorias, como lo es la ganadería extensiva, las explotaciones agrícolas desarrolladas con tecnologías intensivas en utilización de agroquímicos o la extracción no sostenible de recursos renovables y no renovables.

$\mathrm{Al}$ iniciarse la apertura económica se hizo evidente el peso que ejerce la concentración de la propiedad territorial en los costos de la producción agrícola. La participación de la renta de monopolio en la composición de estos costos, añadida a las elevadas tasas de interés y a los costos de los insumos derivados de una política comercial favorecedora de las grandes empresas multinacionales productoras de agroquímicos resta toda competitividad a la producción agrícola nacional.

\section{La Reforma Agraria y el ordenamiento territorial}

La necesidad de eliminar el peso del monopolio de la propiedad agraria en los costos de la producción no estuvo ausente en las motivaciones de la Ley 160, última ley de Reforma Agraria producida en medio del auge aperturista y que, como veíamos, no respondía a propósitos de democratización del acceso a la tierra. Esta Ley, en consonancia con las concepciones neoliberales, hace reposar el reparto agrario en manos del mercado, ilusión que se desvanece al tropezar con la realidad de las fuerzas que sostienen su poder político y económico en la concentración de la propiedad.

$\mathrm{Al}$ reconsiderar el carácter estratégico de las funciones del Estado y su papel en la sostenibilidad del pacto social es necesario considerar, dentro de ellas, las que guardan relación con el reparto agrario como factor político. En circunstancias en las cuales la distribución de la propiedad induce los conflictos más relevantes en un escenario de guerra civil, no puede dejarse prioritariamente en manos del mercado la solución de los desequilibrios en el acceso a la tierra y se hace necesaria la intervención del Estado en ella, con la fiscalización de las comunidades para evitar las prácticas de corrupción que hasta ahora han viciado la acción de reforma agraria en el país.

En este escenario juega un papel estratégico el conjunto de avances logrado para la participación popular en la gestión publica, en particular en lo atinente a la gestión de los recursos naturales y la administración del espacio. La ley 160 de 1994 abrió un margen considerable a la gestión de los municipios y, por ende, a la visión territorial de la reforma agraria; con este margen, contemplado en las funciones que se asignan a las organizaciones civiles de nivel municipal se hace posible superar las acciones puntuales, a nivel de "finca" de la reforma agraria para comenzar a diseñarlas a nivel de municipio, de espacios más amplios. Con ello la reforma adquiere el carácter de instrumento estratégico para el ordenamiento territorial, en el sentido al que se hizo referencia anteriormente.

El desorden característico de la ocupación del territorio nacional ha sido, como ya se señaló, el resultado de una ausencia de Estado, de un vacío en la jerarquización de los componentes del espacio nacional, de la carencia de políticas y orientaciones para el poblamiento, la formación de los asentamientos humanos y el acceso a la tierra. La conjugación de estos factores ha tenido como efectos, además del profundo deterioro ambiental y la ampliación de la pobre$\mathrm{za}$, el surgimiento de condiciones que han puesto en jaque el modelo social, económico y político vigente, muy posiblemente, para bien del país.

Al mismo tiempo, la Carta política reconoce la creciente demanda de las comunidades por ampliar sus campos de decisiones en la gestión del Estado, del territorio y del patrimonio ambiental, con todo lo cual queda en el pasado la pretensión de "ordenar la casa desde arriba", de imponer un ordenamiento del espacio nacional desde la cúpula del Estado central, pretensión que demostró, con creces, su plena inoperancia.

No obstante, el propósito central de la sociedad en su conjunto, de alcanzar un desarrollo sostenible en términos ambientales, económicos y políticos, solamente podrá ser viable con una gestión participativa pero también técnicamente orientada. Es acá en donde se abren las demandas para desarrollar métodos participativos y eficientes para producir un nuevo ordenamiento del territorio y del reparto social.

En este punto, es necesario insistir en el reconocimiento de las realidades presentes en las relaciones entre las comunidades y su medio natural. En primer término, la formulación de cualquier proyecto de esta naturaleza ha de partir de clarificar los objetivos y metas del mismo, sustentados en un diagnóstico adecuado de las condiciones ambientales y humanas del espacio definido como escenario del proyecto.

$\mathrm{Al}$ respecto, se deberá tener en consideración la génesis de los asentamientos, la cual explica, en buena medida, las características y razones del ordenamiento espacial. En segundo lugar, es necesario contar con la valoración de los saberes tradicionales sobre el territorio y sus recursos y, no menos importante aún, establecer las bases y contenidos de la concertación en torno a la ocupación y manejo de los espacios previstos como escenarios de los acuerdos.

El diseño y aplicación de los aspectos instrumentales del proyecto, referidos a inventarios, técnicas de conservación y preservación por aplicar, capacitación, mecanismos de participación, seguimiento y toma de decisiones, etc., son tarea conjunta de técnicos y comunidades.

Por otra parte, el desarrollo de este gran proyecto ha de guardar coherencia con las definiciones estratégicas nacionales sobre destinación de las regiones y ecosistemas, políticas de asentamientos humanos y fronteras, como propósitos de la sociedad y del Estado del corto, mediano y largo plazo. Su base cierta ha de ser la voluntad de preservación y desarrollo de la nacionalidad y de su patrimonio ambiental, sostenible sobre las bases de la convivencia y el respeto mutuo entre quienes la componen y entre ella y su entorno natural.

\section{El conflicto armado y las bases de su superación}

Un factor fundamental en la crisis de las relaciones interregionales que hoy caracteriza al país y al cual habrá de enfrentar un proceso democrático de ordenamiento del territorio son los conflictos armados. Desde hace poco más de una década, ellos se han extendido a gran parte del territorio 
y de los espacios de la vida nacional, reduciendo la gobernabilidad, debilitando las instituciones y la propia soberanía nacional. Al mismo tiempo, surgen con mayor fuerza propuestas de la sociedad y de entidades externas dirigidas hacia la búsqueda de soluciones negociadas para la guerra.

Los analistas del conflicto armado en Colombia coinciden en señalar la importancia de las raíces agrarias del mismo, relacionadas con las profundas inequidades en la distribución de la propiedad territorial, en el acceso a los demás recursos productivos y a los servicios, todo lo cual incide en la profundización de las brechas campo-ciudad, en la persistencia de condiciones de pobreza y pobreza absoluta en el campo y, por último, pero de primera importancia, en la debilidad política estructural de las sociedades rurales, a las cuales se ha impedido, de manera sistemática, de la representación de sus intereses en la concertación nacional.

Un factor fundamental para superar estas condiciones críticas es el referido al gasto público y a la modernización de las condiciones sociales y productivas del campo como responsabilidad del Estado y del conjunto de la sociedad. Las decisiones en este sentido, guardarían correspondencia con una comprensión del significado estratégico del campo para la estabilidad económica y política del pacto social vigente, lo cual expresaría una priorización, a mediano y largo plazo, de las políticas dirigidas al desarrollo rural y a la búsqueda de equilibrios en las condiciones políticas, sociales y económicas entre el campo y la ciudad.

Esta priorización estaría reflejada en el respeto a las organizaciones de campesinos y demás trabajadores del campo como interlocutores en la negociación del reparto político y económico nacional, todo lo cual implica construir un nuevo modelo de desarrollo en el cual se definirían prioridades diferentes en cuanto los objetivos y metas del desarrollo, nuevos equilibrios entre el campo y la ciudad y correlaciones igualmente diferentes entre el manejo macroeconómico y la distribución del producto social.

Este nuevo modelo de desarrollo habría de estar sustentado en una voluntad política consecuente y recursos adecuados. Igualmente, deberá contar con el apoyo de otras políticas que actúen como soporte paralelo y dinamizador. Esta función corresponde a las propuestas de adelantar una política de paz como política de Estado, las cuales coinciden en señalar al problema agrario como base fundamental del conflicto armado.

Existen experiencias similares a la colombiana que deberán ser tenidas en cuenta para desarrollar una política efectiva de negociación y superación de las confrontaciones armadas. Para este efecto se sugiere desarrollar acuerdos de trabajo de "doble vía", que permitan también compartir los aprendizajes realizados por Colombia. Igualmente, se recomienda aprovechar los recursos, capacidades y experiencias de organizaciones internacionales que faciliten el desarrollo de las políticas, programas y proyectos dirigidos a obtener una paz duradera en el país. El tránsito hacia la paz tiene costos para el conjunto de la sociedad, los cuales, sin embargo, resultan ventajosos si se comparan con los costos económicos, sociales y políticos de la guerra.

No obstante, el proceso de reconstrucción (salud, educación, subsidios para la alimentación, apoyo a las organi- zaciones populares, créditos para la producción y la comercialización, vivienda y reasentamientos, dotación de infraestructuras, etc., etc.) requiere recursos que difícilmente pueden ser proporcionados por la economía nacional con la eficiencia requerida para la sostenibilidad del proyecto.

\section{REFERENCIAS BIBLIOGRÁFICAS}

BANCO Mundial (1997): From Vision to Action in the Rural Sector. Washington.

BEJARANO, Jesús A. (1997 a): Las políticas agricolas en los países de la comunidad andina: un análisis comparativo. Santafé de Bogotá: IICA

BejARANo, Jesús A. et al. (1997 b): Colombia: inseguridad, violencia y desempeño económico en las áreas rurales. -Universidad Externado de Colombia- Bogotá: FONADE.

Binswanger, Hans et al. (1993): Power, Distortions, Revolt, and Reform in Agricultural Land Relations, The World Bank. Washington.

Colmenares, Germán (1987): "La Formación de la Economía Colonial (1500-1740)", en OCAMPO, José Antonio (ed.), Historia Económica de Colombia. Bogotá: FEDESARROLLOSiglo Veintiuno.

VARIOS (1996): "Contrato social rural" en Una mirada social al campo. Santafé de Bogotá: Compilación de la Cumbre social rural, Ministerio de Agricultura y Desarrollo rural.

Dane (s.f.): Encuesta Nacional Agropecuaria. Resultados 1995. Santafé de Bogotá.

CONPES, documentos (Diciembre 1994): Modernización rural y desarrollo empresarial.

Domínguez, Camilo (1992): "Geografía Política y Ordenamiento Territorial”, en Varios, Ordenamiento Territorial. Santafé de Bogotá: IGAC-COT-DNPA.

El EsPeCtador (Marzo de 1997). Santafé de Bogotá.

FajARdo, Dario, et. al. (1997): Colonización y Estrategias de Desarrollo. Santafé de Bogotá: IICA - Ministerio del Medio Ambiente.

FAJARDO, Darío (1994): "La política social rural”, en MOSCARDI, Edgardo (ed.), El Agro colombiano ante las transformaciones de la Economía. Santafé de Bogotá: IICA-Tercer Mundo Editores.

FigueroA, Adolfo (1996): Pobreza Rural en los países andinos, ponencia presentada ante el Seminario Internacional sobre Política Agrícola hacia el 2020: la búsqueda de la competitividad, sostenibilidad y equidad. Santafé de Bogotá: IICA.

GARCíA, Antonio (1970): Dinámica de las reformas agrarias en América Latina. Bogotá: La Oveja Negra.

GARCíA, Antonio (1982): Modelos operacionales de reforma agraria $y$ desarrollo rural en América Latina. San José: IICA.

GUTTERMAN, Lía: "El Sector agropecuario frente a la apertura", en MOSCARDI, Edgardo (editor), El Agro colombiano ante las transformaciones de la Economia, (citado).

HeAth, John, KLAus DeININGER (1997): Implementing Negotiated Land Reform: The Case of Colombia. Washington: The World Bank (poligraf.).

Huntington, Samuel P. (1968): Political Order in Changing Societies. New Haven: Harvard University.

LE GRAnD, Catherine (1986): Frontier Expansion and Peasant Frontier in Colombia 1830-1936. Alburqueque: University of New Mexico Press.

LÓPEZ, Ramón y VALDÉZ, Alberto (1996): Determinants of Rural Poverty in Colombia (borrador). Washington.

LORENTE, Luis et al. (s.f.): Distribución de la propiedad rural en Colombia 1960-1984. Bogotá: CEGA. 
MACHADO, Absalón (1984): "Reforma Agraria. Una mirada retrospectiva” en Economía colombiana, 160-161, Agosto - Septiembre. Bogotá.

MÁRQUEZ, Germán (1996): Ecosistemas Estratégicos y otros estudios de Ecología Ambiental, Santafé de Bogotá: Fondo FEN.

MaY, Ernesto (1995): La Pobreza en Colombia. Un estudio del Banco Mundial. Santafé de Bogotá: Tercer Mundo Editores-Banco Mundial.

Mesa (1990), en Ministerio de Agricultura-Departamento Nacional de Planeación, El Desarrollo Agropecuario en Colombia, Informe Final Misión de Estudios del Sector Agropecuario, DNP. Bogotá.

MOORE, Barrington (1993): Social Origins of Dictatorship and Democracy. Boston: Beacon Press.

Mondragón, Héctor (1996): Reforma Agraria y Perspectivas del Campesinado, VIII Foro Nacional: "Paz: Democracia, Justicia y Desarrollo", Santafé de Bogotá.

Mondragón, Héctor (1997): Otra vez el Socialismo. Santafé de Bogotá: Errediciones.

MoSCARDI, Edgardo (1996): Una nota sobre el Desarrollo Rural en América Latina: de los Proyectos de Modernización al "Empowerment" de las comunidades campesinas, (mecanografiado), Santafé de Bogotá.

OCAMPO, José Antonio (1984): Colombia y la Economía Mundial 1830-1910. Bogotá: Siglo XXI.
PerfetTI, Juan J. y GuerRA, M. R. (1993): Los beneficiarios del gasto público social en las áreas rurales. Estudio de incidencia del gasto público social. Santafé de Bogotá: DNP.

RANGEL S., Alfredo (1996): Colombia: la guerra irregular en el fin de siglo. Encuentro colombo-español. Paz y Guerra en conflictos de baja intensidad: el caso colombiano. Santafé de Bogotá.

REYES, Alvaro y MARTínEZ, J. (1994): "Funcionamiento de los mercados de trabajo rurales en Colombia”, en: GONZÁLEZ, Clara y Jaramillo, Carlos Felipe, (Coordinadores), Competitividad sin pobreza. Santafé de Bogotá: Departamento Nacional de Planeación.

SARMIENTO, Libardo (1996): "La pobreza rural en Colombia en el contexto latinoamericano", en Varios, Una mirada social al campo. Compilación de la Cumbre social rural, Ministerio de Agricultura y Desarrollo rural. Santafé de Bogotá.

THoumi, Francisco (1994): Economía politica y narcotráfico. Santafé de Bogotá: Tercer Mundo.

URIBE, Sergio (1997): "Los cultivos ilícitos en Colombia", en Thoumi, Francisco et al., Drogas ilícitas en Colombia. Su impacto económico, politico y social. Santafé de Bogotá: Ariel Ciencia Política.

UTRIA, Rubén D.: “Ordenamiento Ambiental Territorial: Hacia un Enfoque Conceptual”, en Varios, Ordenamiento Territorial, (citado).

\section{RESUMEN}

Para el autor sentar las bases de una paz duradera exige resolver la problemática agraria. El conflicto armado en Colombia tiene hondas raíces rurales, relacionadas con profundas inequidades en la distribución de la propiedad de la tierra, en el acceso a otros recursos productivos y servicios, circunstancias que agudizan las brechas campo/ciudad. Es responsabilidad del Estado y del conjunto de la sociedad resolver esta situación poniendo los medios a su alcance: orientación del gasto público, reforma agraria, fortalecimiento de las sociedades rurales y modernización de las condiciones sociales y productivas del campo, en definitiva, estableciendo un nuevo modelo de desarrollo que resuelva los desequilibrios existentes.

Palabras clave: Colombia, Reforma Agraria, problemática agraria, Distribución de la propiedad territorial, conflictos ambientales

\section{ABSTRACT}

Setting the bases for a lasting peace, for the author, demands the resolution of the agricultural problems. The armed conflict in Colombia has a deep rural roots. These roots are related to deep unequalities in the property distribution and in the acces to other means of production and servicies. All of them are circunstances that stimulate the rift between country and city. Resolving this situation is responsability of the State and the whole society. They must give all the resources at their disposal by orienting the public expenditure, agrarial reform, strenghening of the rural societies and modernizing the social and productive conditions of the country. In conclusion, establishing a new way of development that resolves the existing imbalance.

Key words: Colombia, agrarial reform, agricultural problematic, land property distribution, environmental problems. 


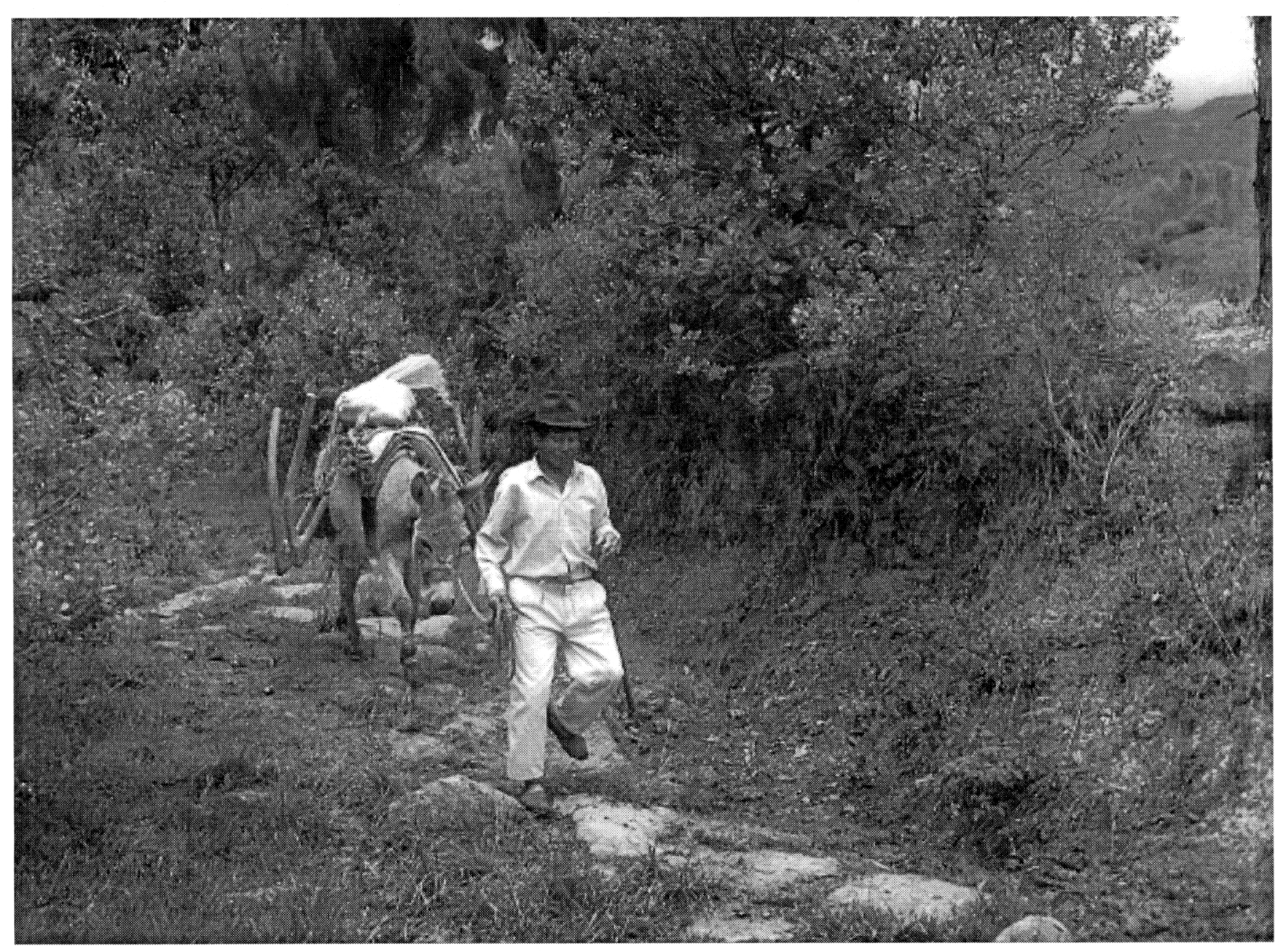

